\title{
RENEWABLE ENERGY: WIND ENERGY, ITS EFFECTS AND ENVIRONMENTAL GAINS
}

\author{
Marcelo Teixeira de Castro ${ }^{1}$, Maciel Gama de Souza $^{2}$, Anderson de Oliveira Castro ${ }^{3}$
}

\author{
${ }^{1,2}$ Centro Universitario do Norte (UNINORTE). Av. Leonardo Malcher, 715 - Centro, Manaus-AM, 69020-010. \\ Fone: +55 (92) 32125000. \\ ${ }^{3}$ Professor Orientador do Centro Universitario do Norte (UNINORTE). Av. Leonardo Malcher, 715 - Centro, Manaus-AM, \\ 69020-010. Fone: +55 (92) 32125000.
}

Email: marcelodecastro211@outlook.com,gamamacie105@gmail.com, anderson.castro@uninort.com.br.

Received: May 21 2019

Accepted: June $15^{\text {th }}, 2019$

Published: September $30^{\text {th }}$, 2019

Copyright $@ 2016$ by authors and Institute of Technology Galileo of Amazon (ITEGAM). This work is licensed under the Creative Commons Attribution International License (CC BY 4.0). https://creativecommons.org/lice nses/by/4.0/

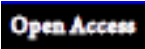

\begin{abstract}
The Brazilian energy matrix is composed of a diverse set of energy generation systems, such as hydroelectric, thermal, solar, wind and other, which aims to meet the demand of our country. A large part of the energy production in Brazil comes from renewable sources, our country is the one that has the greatest capacity to produce energy through the wind when compared to the countries of Latin America. However, as with all power generation technology, the deployment and operation of wind systems has unfavorable environmental impacts, such as: electromagnetic interference, noise, visual impact, wildlife damage. Some of these impacts can be minimized or even eliminated through proper planning and technological innovations. The aim of this work is to gather theoretical foundations on wind energy, its effects on the environment caused by the implantation and operation of these systems.
\end{abstract}

Keywords: Wind Energy, Environmental Impacts, Environmental gains.

\section{ENERGIAS RENOVÁVEIS: ENERGIA EÓLICA, SEUS EFEITOS E GANHOS AMBIENTAIS}

\section{RESUMO}

A matriz energética brasileira é composta por um conjunto diversificado de sistemas de geração de energia, como hidrelétrica, térmica, solar, eólica e outros, que visa atender à demanda do nosso país. Uma grande parte da produção de energia no Brasil vem de fontes renováveis, nosso país é o que possui a maior capacidade de produção de energia através do vento, quando comparado aos países da América Latina. No entanto, como acontece com toda a tecnologia de geração de energia, a implantação e operação de sistemas eólicos têm impactos ambientais desfavoráveis, tais como: interferência eletromagnética, ruído, impacto visual, danos à vida selvagem. Alguns destes impactos podem ser minimizados ou até mesmo eliminados através de um planejamento adequado e inovações tecnológicas. $\mathrm{O}$ trabalho visa reunir fundamentos teóricos sobre a energia eólica, seus efeitos sobre o meio ambiente causados pela implantação e operação desses sistemas.

Palavras-Chave: Energia Eólica, Impactos Ambientais, Ganhos Ambientais.

\section{INTRODUÇÃO}

Este artigo tem a finalidade de descrever os efeitos ambientais ocasionados pela busca de energias alternativas voltadas para as ações setoriais do sistema de energia eólica tendo como foco a natureza sustentável das ações ambientais que caracterizam esse esforço de produção de energia limpa.

Os países em desenvolvimento como o Brasil, ricos em matérias-primas necessitam de uma política energética mais abrangente que possa garantir soluções no futuro, e menor 
dependência econômica e tecnológica em relação aos países desenvolvidos.

A importância do tema é trazer à tona questões que possa elucidar no cenário de alternativas energéticas como o setor de energia eólica tem estruturado os mecanismos institucionais de redução de impactos ambientais.

O tema tratará de evidenciar a implementação de novas usinas de energia eólica bem como as dimensões que marcam a modalidade, considerando-se que atualmente, dá-se muita importância às pesquisas na área de energias alternativas, pode-se analisar a realidade energética do Brasil e as condições de ampliação da energia eólica, assim como os impactos que atualmente se discutem em várias esferas federais e estaduais

Justifica-se a realização do estudo com base no pressuposto de que as ampliações da matriz energética brasileira implicam em diretrizes legais de avaliação de impactos na medida em que atualmente se realizam leilões onde se negociam a energia proveniente dos ventos.

Os discursos sobre a ampliação das ações do sistema setorial brasileiro de energia eólica tendem a considerar que esse tipo de produção se faz por meio de mecanismos limpos, mas é preciso conhecer e analisar os meios de implantação de energia se exige licença ambiental e padrões de redução de impactos.

Desta forma, o tema tem ganhado significativo destaque na mídia nacional, assim como proliferam debates, seminários, prêmio e publicações de autores sobre o meio ambiente.

A gestão ambiental nas empresas é realizada a partir de um conjunto de políticas, programas e práticas administrativas e operacionais que levem em conta a proteção do meio ambiente através da eliminação ou minimização de impactos e danos ambientais em suas atividades produtivas.

O desenvolvimento sócio-econômico produzido no espaço geográfico no capitalismo produz transformações na natureza. Conforme [4], as mudanças ocorrem nas relações entre a sociedade e a natureza e entre as classes sociais no processo produtivo. As transformações se fazem nas dimensões da reprodução de cunho produtivo que produz problemas ambientais que são atualmente focos relevantes de riscos sociais em relação às constantes alterações dos ambientes naturais e seus ecossistemas.

Atualmente os discursos político-ambientalistas evocam a necessidade de utilização de novas alternativas energéticas que possam garantir o consumo crescente e o impacto ambiental e social causados pelas fontes de energias tradicionais, como as hidrelétricas.

No setor de energia elétrica, as decisões de geração de energia eólica, localização e instalação de usinas poderão fornecer uma nova alternativa na matriz energética brasileira. A construção de turbinas eólicas envolve igualmente a avaliação e o monitoramento da área de localização, considerando que sua instalação exige engenharia estratégica e critérios adequados nas tomadas de decisões em relação ao planejamento e logística para identificar todas as variáveis que possam dar uma visão antecipada dos problemas ambientais para que haja coerência no projeto de implantação.

Nesse sentido, o planejamento e gerenciamento ambiental fazem parte de uma operacionalização fundamental quanto à correta aplicação de técnicas de análises.

Demonstra-se no estudo que a implantação de usinas eólicas exige o uso de licença e impõe o desenvolvimento de técnicas e métodos para a avaliação do dano ambiental, a partir do controle ambiental com base em arcabouço legal do Plano Diretor da Cidade.

\section{METODOLOGIA}

A metodologia do estudo se orientou pela pesquisa bibliográfica e exploratória centrada nas contribuições teóricas de vários autores que realizaram estudos sobre os impactos ambientais da energia eólica. Conforme [8], Pesquisa bibliográfica é desenvolvida a partir de material já elaborado, constituído principalmente de livros e artigos científicos. Embora em quase todos os estudos seja exigido algum tipo de trabalho desta natureza, há pesquisas desenvolvidas exclusivamente a partir de fontes bibliográficas.

Assim, verifica-se que a pesquisa bibliográfica é fundamental para o desenvolvimento dos pressupostos de pesquisa. Conforme [5], A bibliografia é um recurso de pesquisa formada por livros, revistas, publicações avulsas e imprensa escrita por especialistas. Portanto, a pesquisa bibliográfica tem a finalidade de colocar o pesquisador em contato direto com a manipulação de suas informações.

O estudo é também de caráter qualitativo e descritivo e tem as funções de proporcionar maiores informações sobre determinado assunto, facilitar a delimitação do estudo e a definição de objetivos ou formulação de hipóteses para desenvolver uma boa pesquisa sobre determinado assunto.

O estudo tem a finalidade de conhecer as contribuições científicas sobre o tema, com base descritiva das características apresentadas pelos vários autores que fundamentaram a pesquisa a partir dos seguintes objetivos, analisar as diretrizes legais que tem sido determinada como forma de regulamentação da produção de energia eólica no Brasil.

\section{ENERGIA EÓLICA E MEIO AMBIENTE: IMPACTOS E GANHOS AMBIENTAIS NA GERAÇÃO DE ENERGIA COM FONTES NATURAIS}

A energia é uma força produtiva essencial para o desenvolvimento, tornando-se todos os países um importante setor de investimentos estatais e privados. O Brasil tem um grande potencial para a produção de energia eólica, as oscilações dos ventos produzem uma velocidade propícia à evolução desse tipo de uso de energia como potencial alternativo.

Conforme [11], a força dos ventos é um tipo de energia que vem usada de forma rudimentar desde tempos antigos, constituindo-se como energia cinética obtida por meio do avanço das massas de ar que produzem ventos que são usados em cataventos em propriedades rurais que obtém a força dos ventos pelo processo de rotação para obtenção de força em trabalhos mecânicos como bombeamento d'água.

Somente no século XIX, a energia eólica passou a ser vista como meio de conversão em corrente elétrica, mas somente com as constantes crises no abastecimento de hidrocarbonetos combustíveis é que as pesquisas e investimentos em energia eólica têm se intensificado em nível mundial.

Segundo [1], e [11], tem havido esforços em torno dos investimentos em torres de energia solar, o avanço das pesquisas nessa área teve uma grande evolução no sentido de buscar transformar a energia solar em energia elétrica.

Existem dois processos para a captura da energia solar: $\mathrm{O}$ processo térmico e o fotovoltaico. O modelo de coleta térmica utiliza a absorção do calor por meio de coletores térmicos que aquecem o ar e a água em residências, hospitais e indústrias.

Os projetos realizados têm sido empregados em dois conceitos em relação a esses processos: o do uso da energia solar de forma concentrada para aquecer as caldeiras na geração de vapor 
e o da conversão direta das radiações solares em energia elétrica através da conversão se realiza por meio de usinas ou torres de energia que utilizam espelhos côncavos como forma de refletir a luz solar e obter o aquecimento necessário para capturar a luz do sol durante a trajetória do dia. Essa energia produz altas pressões nas turbinas e gera corrente elétrica.

O sistema de células fotovoltaicas embora caro e ainda pouco desenvolvido é uma forma de transforma energia solar diretamente na corrente elétrica, atualmente bastante empregado em satélites artificiais. $\mathrm{O}$ uso de células fotovoltaicas é armazenado em baterias solares. Devido ao alto custo atualmente no Brasil sua utilização tem se destacado [7].

No Brasil, atualmente a legislação que reconhece os esforços em matriz energética, assim como o ordenamento da expansão energética tendo como foco a Lei $\mathrm{n}^{\mathrm{o}} 10.438 / 2002$ que instituiu um Programa de Incentivo às energias alternativas voltadas para energia eólica, a implantação de pequenas centrais hidrelétricas e os demais projetos e experiências voltados ao uso de biomassa que atualmente fazem parte do conjunto de ações do governo para serem desenvolvidos até 2020 para acompanhar as necessidades energéticas do Brasil futuramente.

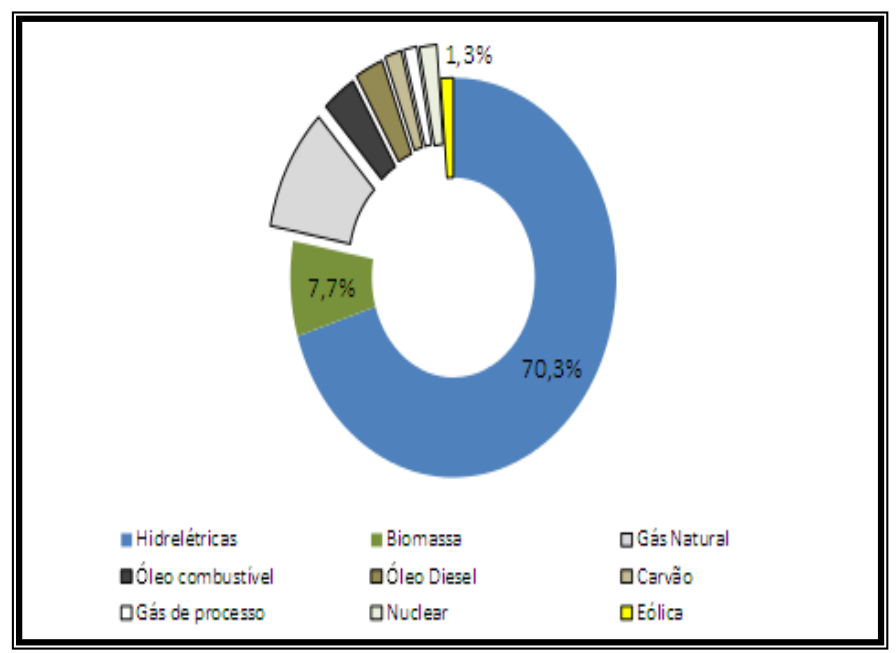

Figura 1 - Matriz energética brasileira. Fonte: (6).

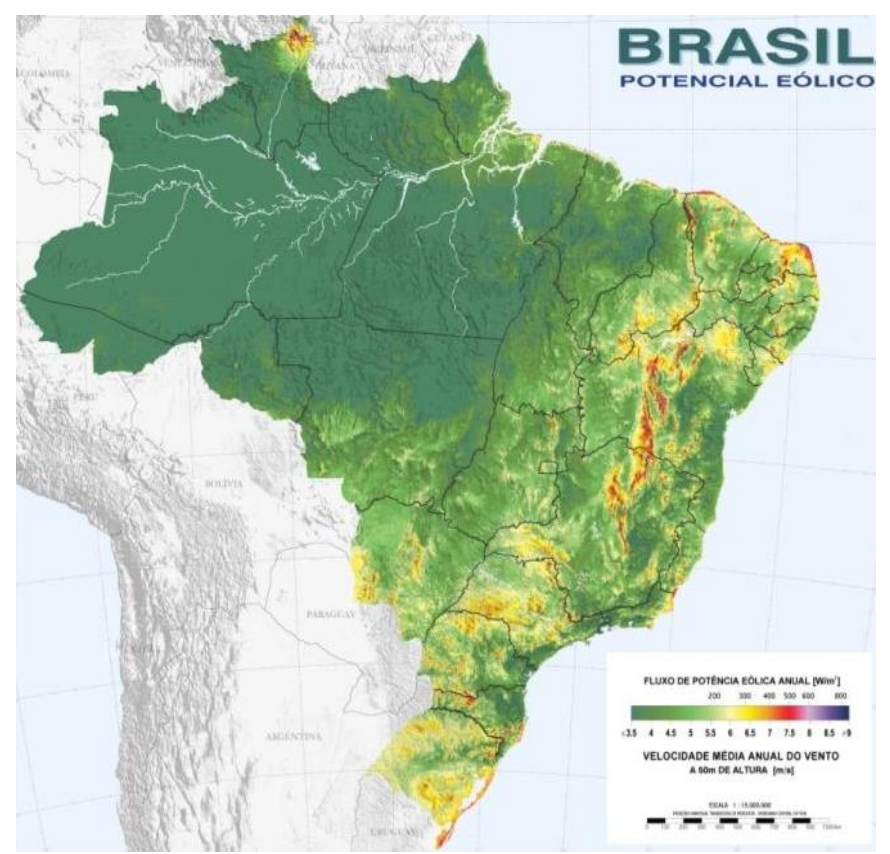

Figura 2 - Mapa do potencial eólico brasileiro. Fonte: (12).

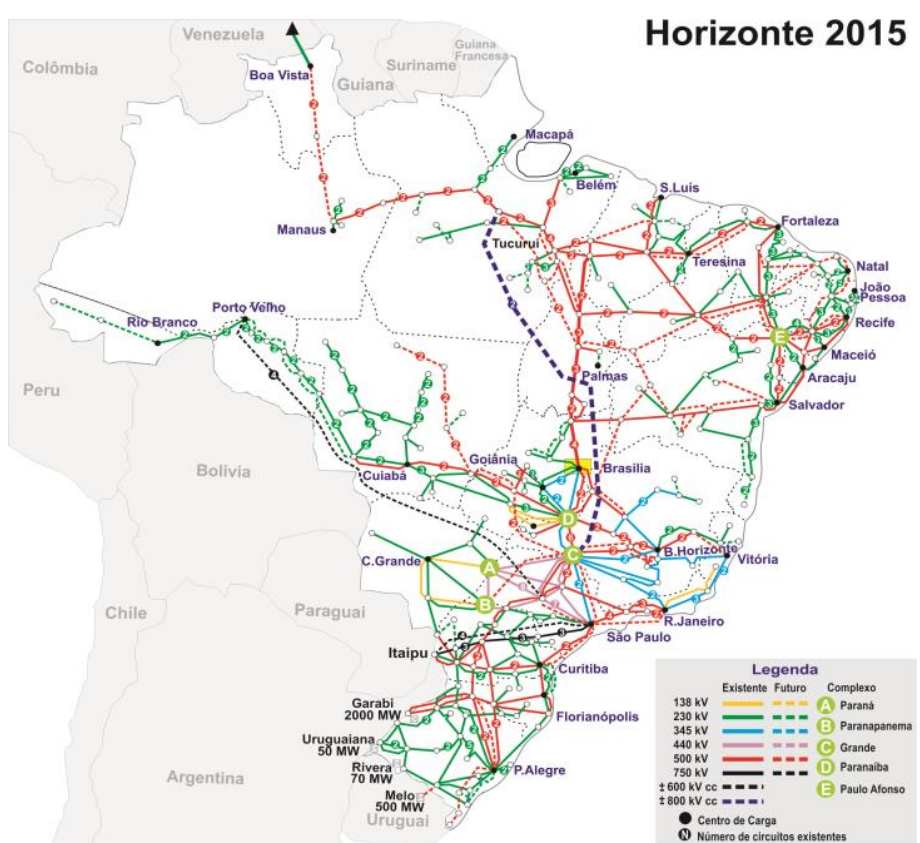

Figura 3 - Sistema Interligado Nacional (SIN). Fonte: (13).

Para atingir esse nível de evolução, o governo brasileiro decidiu efetivar esforços para manter o incentivo aos pequenos produtores de energia gerando uma futura demanda e oferta energética, além de produzir uma maior capacidade de empregos e renda para as populações a partir de estratégias que tem com o foco o aproveitamento de todos os potenciais naturais energéticos de cada região.

Conforme [10], avalia que na atualidade existem muitos países que estão desenvolvendo pesquisas avançadas em parques de energia eólica, fator que implica em capacitação tecnológica para a evolução de energias limpas, como fonte alternativa.

As preocupações ambientais se projetam diante de grandes investimentos que se constata obteve um avanço de capacidade instalada em relação ao crescimento em investimentos anuais instalada no mundo de 2006 a 2011.

Os resultados atuais se apresentam com $27 \%$ em 2006, quando tiveram uma queda de investimentos produtivos em relação ao crescimento anual, em 2007 para 25\%, mas de 1998 a 1999 se estabeleceram entre $34 \%$ e $33 \%$. No ano 2000 obteve um aumento para 37\%. Nos anos seguintes de 2002 a 2004 caiu de $37 \%$ para $21 \%$, mas a partir de 2005 a 2009 voltou a crescer obtendo $32 \%$. Entre os anos de 2010 e 2011 caiu de $24 \%$ para $21 \%$.

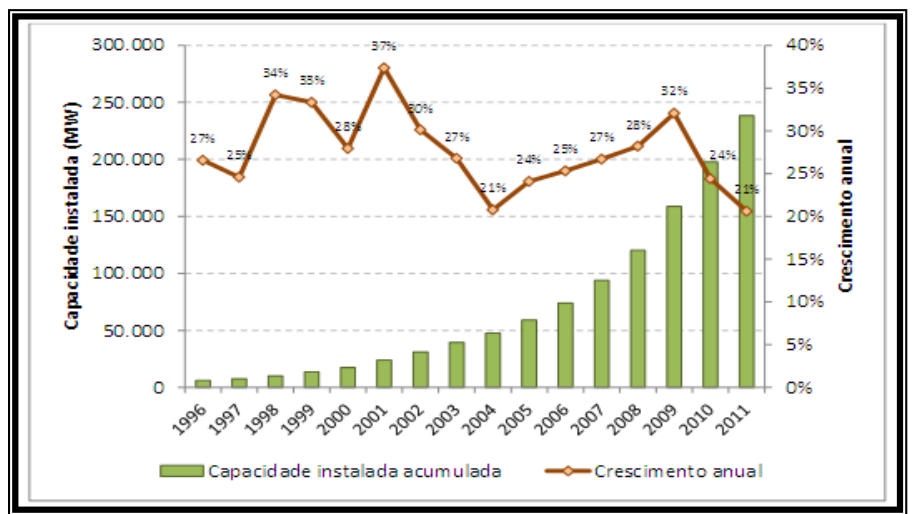

Figura 4 - Relação entre capacidade instalada acumulada e crescimento anual.

Fonte: (7). 
As estimativas de avanço de centrais de grande porte se devem à implantação de um Sistema Interligado Nacional - SIN, que tenderá a garantir o processo de redução de emissões de gases de efeito estufa gerado pelas usinas termelétricas que causam grandes impactos ambientais nos sistemas físicos e bióticos, como os aspectos de caráter social, econômico e cultural das regiões de locação. Segundo [14] estima-se que uma turbina de $600 \mathrm{~kW}$, instalada em uma região de bons ventos, poderá evitar a emissão de 20.000 a 36.000 toneladas de $\mathrm{CO} 2$, dependendo do regime de vento e do fator de capacidade, durante seus 20 anos de vida útil estimado.

Na visão de [10], e [11], o aproveitamento da energia solar na transformação em corrente elétrica apresentam também condições de uso impactantes para o meio ambiente, levando-se em consideração que o Norte e Nordeste Brasileiro tem se constituído de áreas de experimentos técnicos planejados com estimativas de poucos impactos ambientais que têm sido evidenciadas nos empreendimentos que estão andamento em vários estados do Brasil como o Amapá, Amazonas, Bahia, Ceará, Distrito Federal, Espírito Santo, Goiás, Minas gerais, Mato Grosso, Paraíba, Paraná, Piauí, Rio Grande do Norte, Rondônia, Roraima, Santa Catarina, Sergipe [6].

O gráfico abaixo demonstra a potência contratada por cada estado para a obtenção de energia, tendo o Ceará o detentor de maior capacidade contratada.

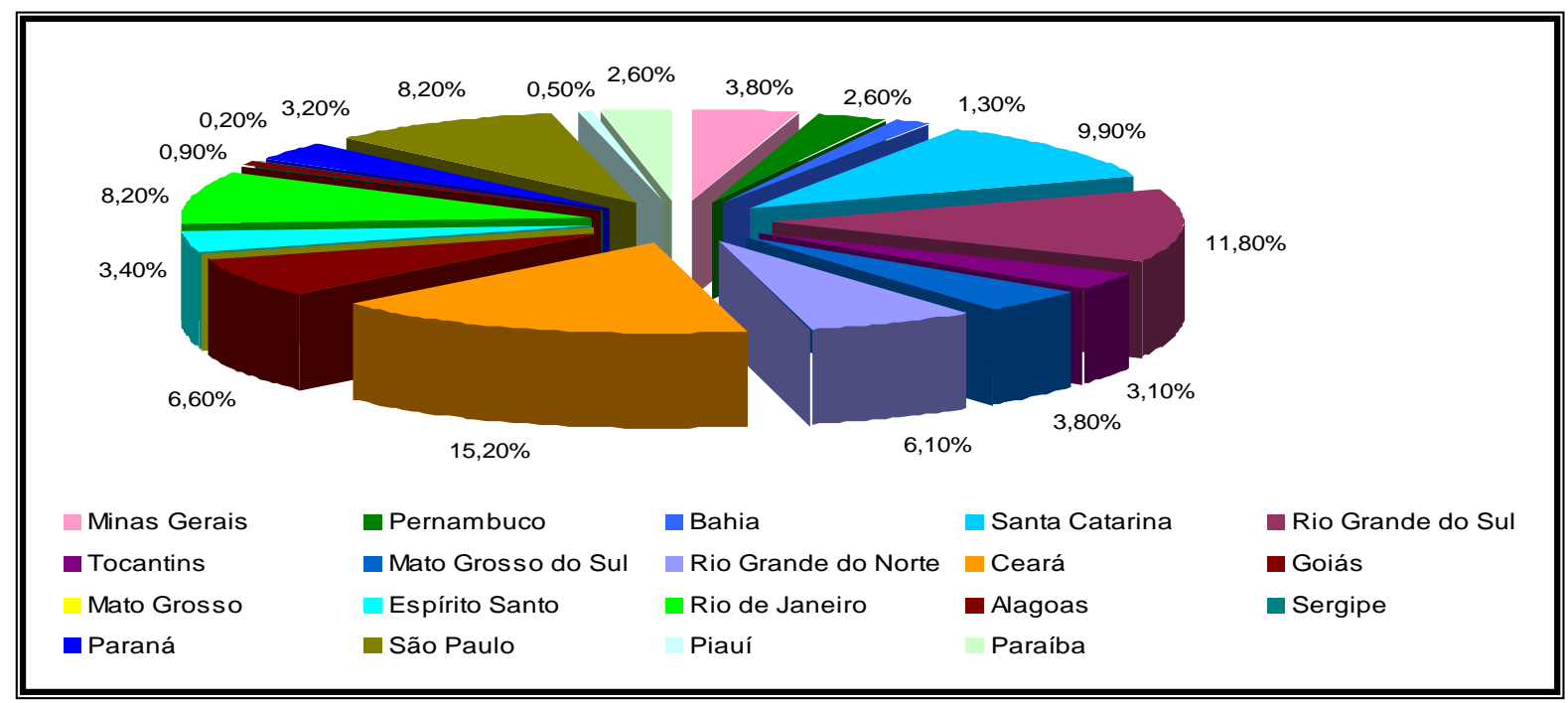

Figura 5 - Potência contratada por Estado. Fonte: (7).

Todo o uso de energia obtida na terra causa algum tipo de impacto ambiental que pode emergir em grandes ou pequenas escalas, mas todos os resultados deverão ser considerados relevantes quando se trata de cenários alternativos na busca de novas energias que causem o mínimo possível de impactos.

Diversos estudos têm buscado apontar a ocorrência possível dos impactos de instalação de projetos que deverão estar sob a fiscalização por parte de órgãos do meio ambiente (IBAMA) e os procedimentos de licenciamento ambiental necessário a esses procedimentos técnicos e a normatização dos polos de evolução de energia eólica.

Deste modo, o processo de geração de energia por meio de turbinas eólicas poderá se expandir de forma expressiva nos próximos 10 anos, passando a ser um tipo de consumo mais viável e com custos reduzidos para a universalização do uso de grande porte de energia eólica.

Por meio do Programa de Incentivo às Fontes Alternativas de Energia Elétrica - PROINFA, as fontes de energia eólica passaram a ter cerca de 50 empreendimentos no Brasil, a partir de potência contratada de 1.422,92 MW, o que garantirá a energia por GWh/ano de 3.719. Em nível de investimento houve um incremento de Custo no valor de $\mathrm{R} \$ 786$ milhões/ano e investimentos de $\mathrm{R} \$ 5,53$ bilhões.

Como se evidencia no gráfico abaixo a energia eólica tem $19 \%$ de contratação por produção com o acumulado de 2006 e 2007.

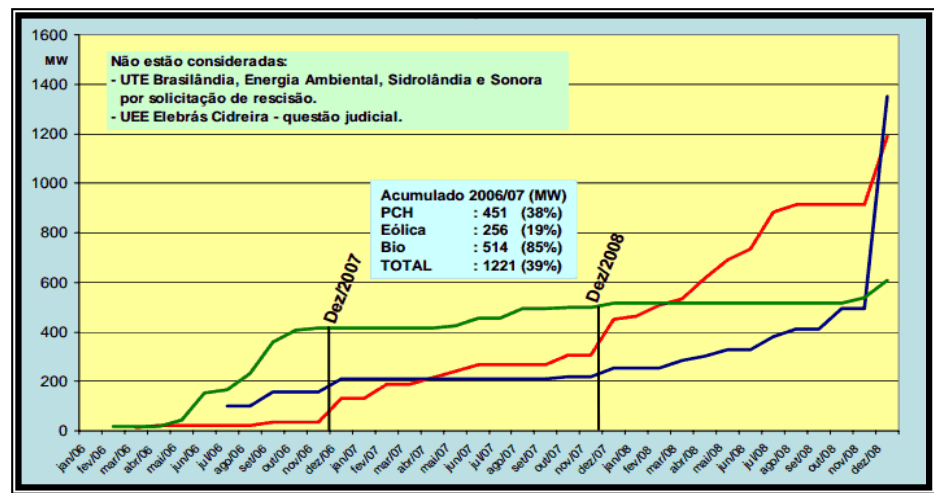

Figura 6 - Contratação por produção do acumulado de 2006/2007. Fonte: (6).

Para incentivar o incremento da energia eólica, o governo brasileiro tratou de determinar as alterações regulatórias para o incentivo de novas oportunidades na produção, por meio da mobilização de leilões de energia em ambiente regulamentado que favorece a negociação em relação ao medidor bidirecional de energia distribuída [9].

Dentre as desvantagens de seu uso é preciso que sejam avaliadas as reais possibilidades de uso da energia eólica em relação ao ambiente. Os objetivos e a situação em que será usada. Outro impacto considerado como, além do visual se constitui no poder de ruídos que geralmente geram problemas para populações locais. Conforme [15], o ruído proveniente das turbinas eólicas tem duas origens: mecânica e aerodinâmica. O ruído mecânico tem sua principal origem da caixa de engrenagens, que multiplica a rotação das pás para o gerador. Muito esforço foi feito desde 1995 no 
desenvolvimento de uma geração de turbinas eólicas agora disponíveis no mercado. O desenvolvimento de tecnologias, ao longo dos últimos dez anos, na aerodinâmica das pás e nas partes mecânicas críticas, principalmente a caixa de engrenagem, tornou possível uma significativa redução dos níveis de ruído nas turbinas modernas.

Os autores analisam que se devem evitar os impactos ambientais por meio de um desenho que favoreça a criação de parques eólicos que possam reduzir os riscos em locais apropriados que possam favorecer a melhor localização e os acessos às turbinas, sem que existam problemas ecológicos nos processos de instalação. Segundo [7], atualmente a existência do Planejamento Integrado de Recursos é uma ferramenta da maior relevância em nível internacional e também nas atividades que envolvem recursos energéticos na realidade brasileira, no sentido de evitar os impactos ambientais gerados pela expansão do desenvolvimento econômico.

No planejamento de ações das equipes de criação de ampliação das ações do sistema setorial brasileiro de energia eólica que deverão ser incorporados por meio do projeto de viabilidade econômica da implantação de aerogeradores a serem instalados no solo e permitir também a relação entre o funcionamento do empreendimento e o nível de impacto sobre o meio ambiente, especialmente sobre a vegetação e a feição do local, assim como os efeitos visuais produzidos no ambiente.

Nessa perspectiva, a minimização de impactos dependerá de determinar no projeto de implantação os devidos espaçamentos entre as turbinas de produção de energia, de modo que se apresentem eficiente em relação ao melhor ambiente de instalação que possa reduzir os riscos de perdas de ventos e perda de velocidade, assim como evitar a ocorrência de acidentes com mortes de aves migratórias.

$\mathrm{Na}$ visão de [6], com a finalidade de evitar impactos ambientais é necessário que o projeto de execução seja realizado por meio de levantamentos e pesquisas científicas e técnicas da área, assim como os níveis potenciais dos ventos na área geográfica onde existem terrenos livres e variação altimétrica que favoreça um ritmo constante de ventos.

Nessa perspectiva, a realização de projetos de implantação de energia eólica exige a instalação de infraestrutura na área escolhida para a execução do projeto. Com a finalidade de desenvolver ações que impeçam os impactos ambientais referentes às medidas de suporte tem sido determinada pelo Plano Decenal de Expansão de Energia - PDE aponta os métodos, as metas e a análise de riscos em impactos ecológicos.

Sob esse ângulo de análise, os fundamentos do processo de expansão de energia não deverão ultrapassar a importância econômica contemporânea, mas é necessário atender aos planejamentos e diretrizes estratégicas de redução de impactos ambientais [9].

Os desenhos dos projetos deverão considerar os critérios de aproveitamento dos ventos usando o mínimo possível o empreendimento, mas usando os aerogeradores de forma estratégica, mantendo um espaçamento entre as torres, a fim de evitar impactos visuais, evitar a execução de projetos em áreas com ecossistemas ecológicos ou em locais que possam causar transtornos nas comunidades de entorno. Portanto, existem impactos que poderão ser amenizados com as medidas que favorecem a melhoria das condições ambientais [3].

As diretrizes do EIA são impostas como base de análise dos empreendimentos por meio de cada projeto e a locação de suas áreas para a implantação de projetos em energia eólica. O licenciamento prévio é um instrumento necessário para ajustar os processos à realidade ambiental para a melhoria dos arranjos de parques eólicos com redução de impactos ambientais [2].
Um empreendimento depende da realização de um projeto técnico que contenha as seguintes etapas:

Quadro 1 - Requisitos para o Projeto.

\begin{tabular}{|c|c|}
\hline FASES & COMPONENTES DO PROJETO \\
\hline \multirow{7}{*}{$\begin{array}{c}\text { Pré- } \\
\text { Implantação }\end{array}$} & Estudos e Projetos \\
\hline & Estudos básicos \\
\hline & Estudo de viabilidade econômica \\
\hline & Levantamento topográfico \\
\hline & Caracterização eólica da região \\
\hline & Projeto \\
\hline & Estudo de Impacto Ambiental \\
\hline \multirow{13}{*}{ Implantação } & Instalação do canteiro de obras \\
\hline & Contratação de construtora / pesscal \\
\hline & Mobilização de equipamentos / materiais \\
\hline & Limpeza da área \\
\hline & Sistema viário (acessos internos) / drenagem superficial \\
\hline & Construção das fundaģ̃es \\
\hline & Montagem das torres \\
\hline & Montagem dos aerogeradores \\
\hline & Montagem elétrica \\
\hline & Subestação \\
\hline & Interligação Elétrica \\
\hline & Testes Pré-operacionais \\
\hline & Desmobilização da obra \\
\hline \multirow{3}{*}{ Operação } & Produção de Energia \\
\hline & Distribuição de Energia \\
\hline & Manutenção do empreendimento \\
\hline
\end{tabular}

Fonte: (6).

O projeto é um passo fundamental para evitar os problemas ambientais, embora não possam ser considerados problemas sérios como nas hidrelétricas e termelétricas que trazem maiores dispêndios em impactos ambientais, a expansão da energia eólica nos próximos anos já está sob a regulamentação ambiental que determina as diretrizes da pré-implantação, implantação e operação.

O processo de distribuição está devidamente regulamentado e as oportunidades de inovações no avanço de novas técnicas em energia eólica podem produzir inovações.

\section{CONCLUSÃO}

O licenciamento ambiental deverá ser um instrumento importante no processo de investigação de impactos por meio de avaliação do terreno para a instalação de turbinas, além da realização de um levantamento planialtimétrico da área do projeto por meio de cartografia que possa definir e detalhar em nível geotécnico a área de construção das turbinas. As organizações privadas ou grupos que desejam realizar a distribuição de energia eólica deverão estabelecer os fins do projeto de empreendimento e tendo como foco a melhor forma de ampliação da energia sem impactos ambientais com a implantação das turbinas que exigem a escavação do solo para colocação eficiente. A realização de leilões de energia eólica tem favorecido investimentos na área de energias alternativas por meio do processo de contratação livre. As empresas que tem interesse na criação de projetos necessitam de documentação legal para a implementação das atividades por meio de matrícula de projeto, certidão do imóvel e o licenciamento ambiental, na medida em que o projeto de implementação deverá estar em conformidade com a lei de uso e ocupação do solo. Essa realidade de uso solo e ocupação é uma forma de respeitar as diretrizes do Plano Diretor tanto em regiões litorâneas como rurais que precisam ser definidas tendo como foco a eliminação de ações inadequadas que tornem o ambiente inaceitável pela comunidade ou restrições pela carência de documentos. 
A atuação das Organizações não governamentais (ONG's), como expressão dos movimentos sociais que atuam como instâncias que avançam na parceria com o Estado e as Empresas Privadas tem tido um forte apelo ambiental nas propostas no sentido de fortalecer o compromisso social em relação às atividades produtivas e a demanda de riscos ao meio ambiente. Tal processo visa discutir conjuntamente os problemas relativos à cooperação e aos desafios colocados para as organizações brasileiras, frente ao contexto da elaboração de projetos de proteção ao meio ambiente com a ampliação do uso de energia eólica.

\section{REFERENCIAS}

[1] Branco, Samuel Murgel. Energia e meio ambiente. São Paulo: Moderna, 2002.

[2] Castro, Nivaldo José de et al. Plano decenal de expansão de energia - PDE 2020:Análise do método, metas e riscos. 2011. Disponível <http://www.nuca.ie.ufrj.br/gesel/tdse/TDSE44.pdf $>$.

[3] Chambel, Sílvia. Estudos de impacto ambiental em parques eólicos uma verdadeira problemática?2007.Disponível em: http://www.ideiasambientais.com.pt/artigos/EIA_eolicos_eternida de.pdf>

[4] Gomes, Ariovaldo. Tecnologias do século XXI em energias alternativas. São Paulo: Atlas, 2007.

[5] Leite, Francisco Tarciso. Metodologia científica: Métodos e técnicas de pesquisa. São Paulo: Ideias \& Letras, 2008.

[6] Oliveira, Adílson de; PEREIRA, Osvaldo Soliano. Energia eólica. São Paulo: SENAC, 2012.

[7] Pinto, Milton Oliveira. Energia eólica. São Paulo: LTC, 2013.

[8] Rodrigues, Auro de Jesus. Metodologia Científica. São Paulo: Avercamp, 2006.

[9] Relatório de Impacto Ambiental - RIMA. Energia Eólica. Disponível em: <http://www.semace.ce.gov.br/wpcontent/uploads/2012/06/RIMA_Guajiru_PDF.pdf >.

[10] Terciote, Ricardo. A energia eólica e o meio ambiente. Enc. Energ. Meio Rural, n. 4, 2002.

[11] Zegna, Glauco. Fontes de energia. São Paulo: Ática, 2003.

[12] Amarante, O. A. C.; Brower, M.; Zack, J.; De Sá, A. L. Atlas do Potencial Eólico Brasileiro. Brasília: Ministério de Minas e Energia, 2001. 45 p.

[13] Operador Nacional do Sistema Elétrico - ONS. Sistema interligado nacional. Brasília, 2015.

[14] Dutra, Ricardo Marques. Viabilidade técnico-econômica da energia eólica face ao novo marco regulatório do setor elétrico brasileiro. 2001. 259f. Tese (Mestrado em Ciências em Planejamento Energético) - Coordenação dos Programas de Pósgraduação de Engenharia da Universidade Federal do Rio de Janeiro, Universidade Federal do Rio de Janeiro, Rio de Janeiro, 2001.
[15] TERCIOTE, Ricardo. A energia eólica e o meio ambiente, UNICAMP - Faculdade de Engenharia Mecânica - Departamento de Energia, Campinas-SP. 